\title{
Professional training for media specialists, school librarians, and teacher-librarians: a program proposal
}

\author{
BLANCHE WOOLLS \\ School of Library and Information Science, San jose State \\ University, San Jose, California
}

\begin{abstract}
Programs to prepare librarians and information professionals of all types often begin with on-the-job training of volunteers, students, and paraprofessionals who go to work in a library while they are in school or as part-time of full-time employment when such non-professional jobs are available. On-site training is not unusual. in earty days of libraries, librarians were often trained through an apprentice-type program.

The newest methods for training librarians include an expansion of a tried and true "distance" plan, the "correspondence" course method where lessons were mailed to the students and the responses returned to the instructor through the mail. The newest form of "mail" is now electronic. In addition, students are able to "attend" classes through electronic transmission in a variety of formats.

This paper traces the beginning of a distance education program at a single institution and highlights the rapid expansion because of an acute need for school librarians. It details the plans for the future which has a forecase for exchange of teachers and students via distance education between sites throughout the world.
\end{abstract}

Many persons who begin work in libraries are given on-the-job training as volunteers, students, paraprofessionals. Their library careers start while they are in high school or college. They may volunteer where their children attend school; others begin as part-time or full-time paraprofessionals in non-professional jobs because they are available. On-site training for "temporary" persons is not unusual. However, as the need for more skills becomes apparent, these persons opt to enroll in specialized training.

In the early days of libraries in the United States, librarians began working through an apprentice-type program in the library, and gradually, they assumed more and more responsibility. This was changed as formal training programs attached to libraries were established. It was this author's privilege to teach for many years at the University of Pittsburgh whose first class in 1900 was given for children's librarians at the Carnegie Library of Pittsburgh.

At the present time, the need for trained information professionals is growing. Not only is attrition through retirements creating a need for new professionals, the need for different skills because of the new technologies has created the need for re-training in staff development and continuing education programs. The interesting thing is that some of the

Education for All: Culture, Reading and Information, /ASL, 1998 
skills needed can be taught using technology to teach as well as to practice. In a sense, it is a form of apprenticeship when one learns how to use the technology as one uses the technology. Others use older forms of teaching materials.

Present methods for educating librarians include an expansion of a tried and true distance plan, the correspondence course, where lessons are mailed to the student and the responses returned to the instructor through the mail for review. The newest form of "mail" is now electronic, and lessons are given, discussion held among students in the class and the instructor through connections to the Internet. Other students are able to attend classes through electronic transmission in a variety of formats from viewing a videotape to interactive classrooms that permit students to see and listen to the instructor and each other at sites many miles apart.

This paper will trace the beginning of distance education at a single institution and trace the rapid expansion because of an acute need for school librarians. It will highlight the plans for the future which forecast the possibility of an exchange of teachers and students via distance education between sites throughout the world.

\section{San Jose State University: present}

The roots of distance education at the School of Library and Information Science are found in the unsuccessful attempts of another of the California State University system institutions, California State University at Fullerton. For several years, a program was in place on this Southern California campus offering courses for those who wished to become librarians. The number of full-time faculty assigned to the program and the financial support that was offered was not sufficient for the American Library Association's Committee on Accreditation to grant approval for that program. When University administrators and librarians in the area realized that no program of their own would be successful, they asked the administration at San lose State University if that program could expand to Southern California located in office and classroom space on the Cal State Fullerton campus. Since that time, full-time tenure stream faculty from the San Jose State University staff have been located in Fullerton. While this off-campus program has been offered through the Continuing Education Department of SJSU, it is an integral part of the SJSU School of Library and Information Science.

The Fullerton program expanded to teach students in Pasadena, San Diego, and San Marcos. Many of the classes are taught by adjuncts, and other classes are transmitted over interactive video from San Jose to Fullerton or from Fullerton to San Jose. Depending upon interest of students and willingness of faculty, these telecommunications courses may be taught by full-time or adjunct faculty at either site. An almost equal number of students (300) are enrolled on each campus for a total of more than 600 students in the SLIS.

In Fall, 1997, two new sites were opened north of San lose. The first, in Sacramento, offered two courses at the Sacramento Public Library. In Spring, 1998, the Sonoma site opened with two classes being taught at California State University Sonoma. One of these courses originated at Sonoma and was transmitted over interactive video to Sacramento with the faculty member teaching from Sacramento to Sonoma for three sessions. The other course was taught between San Jose, Sacramento, and Sonoma with the primary location in San jose and the instructor traveling two times each to the other sites. 
At both San Jose and Fullerton, full MLIS programs are offered with the three-course core taught in San Jose Fall, Spring, and Summer. The core is taught in Fullerton only in the Fall and Spring. Faculty agreed that, at any distance site, the core should be offered within each 12-month period. If this was not possible, new sites should not be added. In order to be cost-accountable, another requirement is that courses have an enrollment of 15 students for any course to be offered. This number is sometimes smaller if another course being taught has a larger enrollment to off-set any course with fewer students than 15 .

The success of these distant programs can be attributed to several reasons. The first is a need for persons who hold paraprofessional positions in school and public libraries and wish to upgrade their positions. For many years, funding in California was reduced; a better economic climate now exists and the need for professional positions is growing in both public and school libraries. Paraprofessionals, many of whom hold bachelor's degrees with additional training at the community college associate's level know that promotion will require the MLIS.

Further, in terms of geography, California is a very large state. Many students are unable to travel to Fullerton or San Jose for single classes because of the distances. For a student who lives in San Diego (the South tip of California) to Fullerton would be a commute of two hours on very busy freeways. The drive from San Jose to Fullerton is six hours, again on very busy freeways. Coming into San Jose from Sacramento (two hours) or Sonoma (almost two hours) can be delayed by stop and go traffic and the time doubled. This does not take into account the far north CSU colleges in Chico (which is an hour from Sacramento) or Humboldt. which is north and west of Chico.

Very few students attend either campus full-time, and most work at least part-time while they are attending. Family or financial reasons make it impossible to move to campus and attend classes either full-time or part-time. Many of our students are returning to the workforce after raising families or are, as stated before, hoping to upgrade their positions. The faculty recognized the need to provide opportunities for those interested in attaining the MLIS degree but unable to attend classes full-time.

The most recent need has been for school library media specialists. As the once high scores of students in California dropped to the lowest in the nation, school administrators are beginning to recognize that the absence of a school library with a school librarian could be a factor in this statistic. For all of these reasons, the faculty, led by one member, Distinguished Visiting Professor Ken Dowlin, has begun planning a Virtual Library School that could offer our MLIS degree and the California Department of Education credential for school librarians at each of the other 21 CSU campuses.

The MLIS degree has not been the only incentive for librarians to wish to attend San Jose's program. A survey conducted by the University of California at Berkeley's Continuing Education Program indicated a strong need for continuing education in library and information science. Additional evidence exists that libraries, schools, and the private sector with the many software companies in California will be hiring approximately 2000 graduates during the next ten years. However, the greatest growth will be in the basic education market, the K-12 schools.

San Jose's School of Library and Information Science is in a unique position to offer the array of courses needed by both new and experienced librarians. As one of the 23 
members of the California State University system which is the largest university in the world, we offer the only program accredited by the American Library Association's Committee on Accreditation.

When San Jose divided its SLIS program for two campuses, they began plans for transmitting library science offerings over telecommunications links. A grant developed by the former Director provided funding to create two ATM classrooms, one in San Jose for the North site and the other at CSU Fullerton for the South site. Each classroom has full multimedia capability for use of video teaching, computer generated and adapted files, and interactive classrooms where students may participate in the discussion from their seats at each of the sites.

The need is great to have adequate technology that will provide an almost seamless interaction between classrooms (and this takes on-site technology experts in times of transmission failure). However, the greatest challenge has been, not the technology to deliver content, but the capability of the faculty to create the syllabus, lecture, and discussion outlines needed to make this as effective as possible. With the advent of video streaming, this connection continues to improve. Care must be taken or the technology to drive the content rather than have the technology assist in providing content.

\section{San Jose State University: the future}

In order for us to expand our program, we are planning to implement a virtual library school that will transmit an instructional program to the 18 sites of the CSU system not currently offering library education with an ALA accredited program. One CSU campus's program provides California credentials for persons interested only in working in school libraries. Because the faculty member in charge of this program is considering retiring, it may that this program will be folded into the current SISU program.

In order to implement our Virtual Library School, we will need a virtual setting. We will be joining a Virtual University, "a dynamic educational institution that is not bounded by geographic barriers, is not limited to physical, static campuses, and delivers education to remote areas." Professor Dowlin's belief is that this University must have a Virtual Library that will have both hard copy and electronic records which have been collected or for which access rights have been negotiated. These records must have long-term access by students and the content should support the Virtual University. One of the components of the new program will be instructor decisions concerning what content must be placed in the Virtual Library for MLIS students. This will also be predicated upon the definition of our School.

The Virtual Library School will be "a discipline centered organization of faculty, content, and a network of people and technology" that will provide a focus in our educational program. Because we are an accredited library school, we must see that our program meets the high level of expectations designed by the ALA Committee on Accreditation. It is thought by Dowlin that

The convergence of technology and politics is being further pushed by the expectations of the consumers (the students) who are becoming not only technologically literate at an age that is dropping every year but are increasing their expectations of educational institutions to include:

- Real time communication 
- Global access to resources

- Student focused programs

- Geographic independence

SJSU is planning to increase real-time communication. The faculty decided that face-to-face, in person instruction is essential for students whenever possible if they are going to be comfortable with televised classes or classes which appear only on the Internet.

Clobal access to resources, in one sense, is a reality because of the World Wide Web. Students at all levels may search for information on sites available for free and through subscription. The ability to link web sites to a faculty member's syllabus means that students can be directed to the best possible sources rather than waste time in searches that aren't productive. It resembles the faculty member who gives students a bibliography as opposed to expecting students to locate their own resources.

One of the critical issues remains to keep course work student focused. Whether offered in the "regular" classroom with an on-site instructor in the more "traditional" model of so many hours per week for so many weeks or in some distance education configuration, the course content must be focused on what students need to learn, the theory they must digest, and the practice that will prepare them, not only for the present, but for the future. Technology supports the curriculum and does not dictate what is taught. Technology is used to provide instruction when that method is the best way to transfer the information. Teachers must plan carefully to integrate the use of technology when that is the appropriate means to transmit knowledge and not feel outdated if an older method works better.

Global independence is created as we move into a global society. Distances shrink as cities, states, and countries move onto the information superhighway. The desire to compete in a global economy has made governmental officials in all nations concerned about providing their citizens with access to this new method of communication. Teachers at all levels of education are well aware that their students will not do well if they leave school lacking in skills to use Internet resources. This does not mean that every country has the financial resources or, in some cases, the electricity or telephone lines to support communications systems that require computers. It does mean that they recognize what must happen and can plan for progress toward that goal.

The critical need becomes trained information professionals who are available to help others locate, choose, and use the best information from the web sites that grow daily. These professionals also help locate new resources to expand access to information. They also work to see that the best access modes are chosen whether communication links to online resources or print, CD-ROM, or other formats.

\section{Global connection}

Once courseware has been designed, it is a simple matter to transmit the content to students wherever they might reside. Further, an instructor need not be on-site to send instructional content to students. This means that professors in Israel might send a course to San Jose and a San Jose instructor might transmit a course to Israel. The major stumbling block would be the language of the instruction. However, as technology expands and refines, this too will be overcome. 
What is most exciting of all is that IASL can begin the communication process among school librarians to see that connections are made. The IASL listserv and web site so admirably managed by Anne Clyde provides a sample of what is to come.

The web site at San Jose State University's School of Library and Information Science is another example of what is currently available for students in California who wish to attend as an academic student or as a continuing education professional school librarian. Expanding this site to other locations throughout the world relies upon our communicating with each other. We at SJSU stand ready to begin the process. 